ERRATUM

doi:10.1038/nature11828

\title{
Erratum: Making sense of palaeoclimate sensitivity
}

PALAEOSENS Project Members

Nature 491, 683-691 (2012); doi:10.1038/nature11574

The surname of author V. Masson-Delmotte was misspelled as Masson-Demotte. In Table 1 of this Perspective, the 'Source' for 'Label in Fig. 3' entry 13 should be ref. 61 (not ref. 65). In addition, the $x$-axis labels of Fig. $3 \mathrm{c}$ were misplaced. Figure 1 shows the corrected panel and the original Perspective has been corrected online.

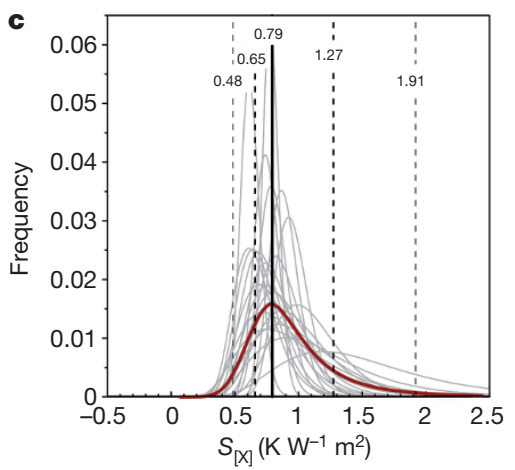

Figure $1 \mid$ This is the corrected Fig. 3c. 